NASA/TM-2007-214980
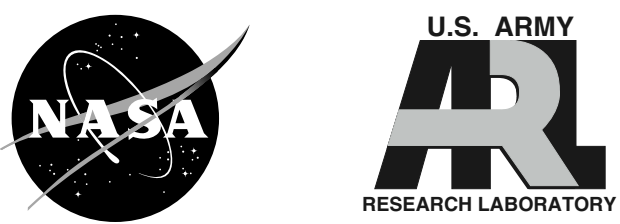

\title{
Integration of On-Line and Off-Line Diagnostic Algorithms for Aircraft Engine Health Management
}

Takahisa Kobayashi

ASRC Aerospace Corporation, Cleveland, Ohio

Donald L. Simon

U.S. Army Research Laboratory, Glenn Research Center, Cleveland, Ohio 


\section{NASA STI Program . . . in Profile}

Since its founding, NASA has been dedicated to the advancement of aeronautics and space science. The NASA Scientific and Technical Information (STI) program plays a key part in helping NASA maintain this important role.

The NASA STI Program operates under the auspices of the Agency Chief Information Officer. It collects, organizes, provides for archiving, and disseminates NASA's STI. The NASA STI program provides access to the NASA Aeronautics and Space Database and its public interface, the NASA Technical Reports Server, thus providing one of the largest collections of aeronautical and space science STI in the world. Results are published in both non-NASA channels and by NASA in the NASA STI Report Series, which includes the following report types:

- TECHNICAL PUBLICATION. Reports of completed research or a major significant phase of research that present the results of NASA programs and include extensive data or theoretical analysis. Includes compilations of significant scientific and technical data and information deemed to be of continuing reference value. NASA counterpart of peer-reviewed formal professional papers but has less stringent limitations on manuscript length and extent of graphic presentations.

- TECHNICAL MEMORANDUM. Scientific and technical findings that are preliminary or of specialized interest, e.g., quick release reports, working papers, and bibliographies that contain minimal annotation. Does not contain extensive analysis.

- CONTRACTOR REPORT. Scientific and technical findings by NASA-sponsored contractors and grantees.
- CONFERENCE PUBLICATION. Collected papers from scientific and technical conferences, symposia, seminars, or other meetings sponsored or cosponsored by NASA.

- SPECIAL PUBLICATION. Scientific, technical, or historical information from NASA programs, projects, and missions, often concerned with subjects having substantial public interest.

- TECHNICAL TRANSLATION. Englishlanguage translations of foreign scientific and technical material pertinent to NASA's mission.

Specialized services also include creating custom thesauri, building customized databases, organizing and publishing research results.

For more information about the NASA STI program, see the following:

- Access the NASA STI program home page at http://www.sti.nasa.gov

- E-mail your question via the Internet to help@sti.nasa.gov

- Fax your question to the NASA STI Help Desk at 301-621-0134

- Telephone the NASA STI Help Desk at 301-621-0390

- Write to: NASA Center for AeroSpace Information (CASI) 7115 Standard Drive Hanover, MD 21076-1320 
NASA/TM-2007-214980
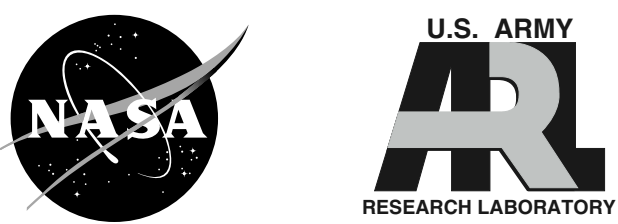

\section{Integration of On-Line and Off-Line Diagnostic Algorithms for Aircraft Engine Health Management}

Takahisa Kobayashi

ASRC Aerospace Corporation, Cleveland, Ohio

Donald L. Simon

U.S. Army Research Laboratory, Glenn Research Center, Cleveland, Ohio

Prepared for

Turbo Expo 2007

sponsored by the American Society of Mechanical Engineers

Montreal, Canada, May 14-17, 2007

National Aeronautics and

Space Administration

Glenn Research Center

Cleveland, Ohio 44135 


\section{Acknowledgments}

This research was funded by the NASA Aviation Safety Program as a task under the Integrated Vehicle Health Management Project.

Level of Review: This material has been technically reviewed by technical management.

Available from

NASA Center for Aerospace Information 7115 Standard Drive

Hanover, MD 21076-1320
National Technical Information Service 5285 Port Royal Road Springfield, VA 22161

Available electronically at http://gltrs.grc.nasa.gov 


\title{
Integration of On-Line and Off-Line Diagnostic Algorithms for Aircraft Engine Health Management
}

\author{
Takahisa Kobayashi \\ ASRC Aerospace Corporation \\ Cleveland, Ohio 44135 \\ Donald L. Simon \\ U.S. Army Research Laboratory \\ Glenn Research Center \\ Cleveland, Ohio 44135
}

\begin{abstract}
This paper investigates the integration of on-line and offline diagnostic algorithms for aircraft gas turbine engines. The on-line diagnostic algorithm is designed for in-flight fault detection. It continuously monitors engine outputs for anomalous signatures induced by faults. The off-line diagnostic algorithm is designed to track engine health degradation over the lifetime of an engine. It estimates engine health degradation periodically over the course of the engine's life. The estimate generated by the off-line algorithm is used to "update" the on-line algorithm. Through this integration, the on-line algorithm becomes aware of engine health degradation, and its effectiveness to detect faults can be maintained while the engine continues to degrade. The benefit of this integration is investigated in a simulation environment using a nonlinear engine model.
\end{abstract}

\section{Introduction}

Early detection of faults is an important aspect in the health management of aircraft gas turbine engines. Undetected faults can lead the aircraft engine into an undesirable operating condition where compressor stall margin is reduced or turbine temperature is higher than the expected value. Under such a condition, safety and efficiency of engine operation may be compromised. Thus, it is critical to detect faults as early as possible and take the necessary corrective actions to avoid undesirable engine operation.

To achieve a real-time fault detection capability, on-line diagnostic algorithms have been developed by several researchers (refs. 1 to 4). An on-line diagnostic algorithm is designed to run on an on-board engine computer in real time. It processes measured engine outputs to detect and, if possible, isolate a fault. Fault detection is pursued based on the fact that the measured engine outputs deviate from their reference condition values when an aircraft engine experiences a fault. An on-line diagnostic algorithm, however, encounters a challenge in achieving reliable performance. This challenge arises from the fact that the measured engine outputs are influenced not only by faults but also by engine health degradation. Engine health degradation is a normal aging process that all aircraft engines will experience due to usage and therefore is not considered as a fault, whereas a fault is an abnormal, unexpected event. Given the measured engine outputs, it is difficult to discern whether the engine output deviations are due to a fault or health degradation. Unless this issue is addressed, the on-line diagnostic algorithm will lose its effectiveness to detect faults as the engine degrades over its lifetime.

One approach to address the above issue is to integrate the on-line diagnostic algorithm with an off-line trend monitoring algorithm. The task of an off-line trend monitoring algorithm is to track the engine health condition over the lifetime of an engine. It estimates the engine health condition based on steady-state engine output data recorded during flight (refs. 5 to 7). Since health degradation is a gradual process, the offline algorithm needs to update its estimate at a relatively low frequency, such as once per a few flights or days. This periodically updated knowledge of engine health condition can be used to adjust the on-line diagnostic algorithm. Through this integration, the on-line diagnostic algorithm becomes aware of health degradation, and its effectiveness to detect faults can be maintained while the engine continues to degrade.

In this paper, an on-line fault detection algorithm and an off-line trend monitoring algorithm are integrated, and the benefit of this integration is investigated in a simulation environment. The on-line fault detection algorithm is based on the hybrid Kalman filter (refs. 8 and 9), and the off-line trend monitoring algorithm is based on the extended Kalman filter (ref. 10). In the following sections, the details of each algorithm are described, followed by the application of the design methodology to a large commercial aircraft engine model. Then, the effectiveness of the integrated diagnostic approach is evaluated using simulated examples of health degradation and faults.

\section{Nomenclature}

\section{BST Booster}

EKF Extended Kalman filter

HKF Hybrid Kalman filter

HPC High Pressure Compressor 


$\begin{array}{ll}\text { HPT } & \text { High Pressure Turbine } \\ \text { LPT } & \text { Low Pressure Turbine } \\ \text { OBEM } & \text { On-Board Engine Model } \\ \text { P2 } & \text { Engine inlet pressure } \\ \text { P25 } & \text { HPC inlet pressure } \\ \text { Pamb }_{\text {ambient pressure }} & \text { Ambier } \\ \text { PLA } & \text { Power Lever Angle } \\ \text { PS3 } & \text { Combustor inlet static pressure } \\ \text { T2 } & \text { Engine inlet temperature } \\ \text { T25 } & \text { HPC inlet temperature } \\ \text { T3 } & \text { Combustor inlet temperature } \\ \text { T49 } & \text { LPT inlet temperature } \\ \text {T}_{\text {amb }} & \text { Ambient temperature } \\ \text { TCM } & \text { Turbine clearance model } \\ \text { TMHS23 } & \text { BST metal temperature } \\ \text { TMHS3 } & \text { HPC metal temperature } \\ \text { TMHS41 } & \text { HPT nozzle metal temperature } \\ \text { TMHS42 } & \text { HPT metal temperature } \\ \text { TMHS5 } & \text { LPT metal temperature } \\ \text { TMSHBC } & \text { Combustor case metal temperature } \\ \text { TMHSBL } & \text { Combustor liner metal temperature } \\ \text { VBV } & \text { Variable bleed valve } \\ \text { VSV } & \text { Variable stator vane } \\ \text { WF36 } & \text { Fuel flow } \\ \text { WSSR } & \text { Weighted Sum of Squared Residuals } \\ \text { XN12 } & \text { Fan speed, measured } \\ \text { XN25 } & \text { Core speed, measured } \\ \text { XNH } & \text { Core speed, actual } \\ \text { XNL } & \text { Fan speed, actual } \\ e & \text { Environmental parameter vector } \\ h & \text { Health parameter vector } \\ u_{c m d} & \text { Control command vector } \\ v & \text { Sensor noise vector } \\ x & \text { State variable vector } \\ y & \text { Sensor output vector (controls/diagnostics) } \\ z & \text { Sensor output vector (ambient/engine inlet) } \\ & \end{array}$

\section{Problem Background: Influence of Faults And Health Degradation}

Although aircraft gas turbine engines are highly reliable, they may encounter numerous types of faults during flight. Sensor faults are most likely to occur (ref. 1), but rotating components and actuators may also experience faults. When an aircraft engine experiences a fault, the measured engine outputs deviate from their reference condition values. Therefore, fault detection can be accomplished by monitoring for shifts in measured engine outputs induced by faults. This is, however, a challenging problem since shifts in measured engine outputs are induced not only by faults but also by engine health degradation. Engine health degradation is the result of usage and manifests itself as degraded performance of engine components such as compressors and turbines. As it worsens gradually over time, the deviation of the measured engine outputs from their reference condition values increases.
Figure 1 shows the influence of health degradation and faults on a measured engine output. The horizontal axis indicates the sample index with a relatively long time interval (e.g., a few flights or a few days). The vertical axis indicates the measured engine output at a specific flight condition. The reference is an expected value of that engine output, and it is derived at a specific health baseline (e.g., nominal health condition). The gradual deviation of the engine output from the reference indicates the influence of health degradation. The discrete jump from point "a" to point "b" at the $k^{\text {th }}$ sample indicates fault occurrence. At the sample point $k$, the engine output shift $\Delta_{\mathrm{k}}$ from the reference is induced by health degradation while a fault induces additional shift $\delta \Delta$. Thus, the total shift $\left(\Delta_{\mathrm{k}}+\delta \Delta\right)$ is observed through a sensor. An on-line diagnostic algorithm, in general, has to process this total shift in order to detect the fault. If the algorithm does not have the capability to handle the health degradation-induced shifts in the sensor measurements, it may either miss the fault or generate a false alarm. Missed detection may occur when the fault is masked by health degradation. A false alarm may be generated when health degradation is misdiagnosed as a fault. Either way, the on-line algorithm will eventually lose its diagnostic effectiveness.

To address the problem described above, the integration of an on-line fault detection algorithm and an off-line trend monitoring algorithm was proposed in references 8 and 9 . The integration architecture of the two diagnostic algorithms is shown in figure 2 . The on-line algorithm processes measured

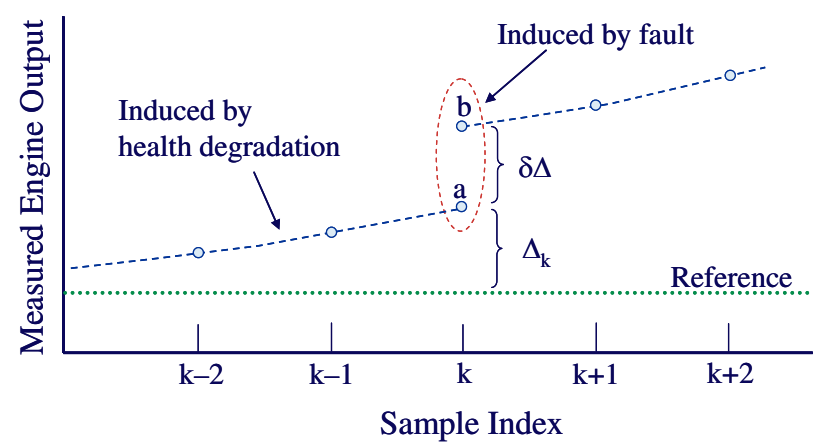

Figure 1.- Influence of health degradation and faults.

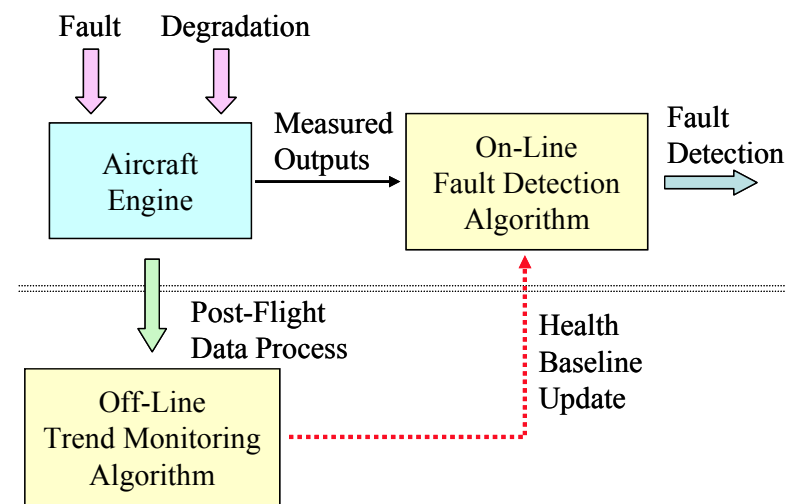

Figure 2.-Architecture of integrated diagnostic approach. 
engine outputs in real time to detect faults during flight. Such an algorithm is generally developed at a specific health baseline, and its reference for measured engine outputs is fixed. Therefore, the measurements processed in real time contain health degradation-induced shifts, which gradually increase over the lifetime of an engine. To account for the influence of health degradation, the health baseline of the online algorithm must be updated periodically so that the algorithm can operate in the vicinity of the degraded engine's health condition. Through the health baseline update, the reference for measured engine outputs is shifted to the vicinity of the degraded engine's outputs (for instance, the reference is shifted to the vicinity of point "a" in fig. 1). Consequently, the health degradation induced-shifts that the on-line algorithm encounters are significantly reduced as compared to the fixed reference case.

The health baseline which is needed to update the on-line algorithm is provided by the off-line trend monitoring algorithm as shown in figure 2. The off-line algorithm processes data post-flight to estimate the health condition of the degraded engine. This data may contain engine outputs recorded at a single or multiple operating conditions. Since health degradation is a gradual process, the frequency at which the off-line algorithm operates is much lower than that of the on-line algorithm.

The algorithms used in this paper for on-line and off-line diagnostics are based on model-based estimation techniques. The on-line algorithm for fault detection is based on the hybrid Kalman filter (HKF) technique. The HKF is a uniquely structured Kalman filter which lends itself to the health baseline update. The off-line algorithm for trend monitoring is based on a derivative of the extended Kalman filter (EKF) technique. A description of each algorithm is given in the following sections.

\section{Integration of On-Line and Off-Line Diagnostic Algorithms}

The on-line and off-line diagnostic algorithms discussed in this section are based on a well-known estimation technique: the Kalman filter. Both algorithms update their estimations as new measurement data become available. The major factor that differentiates these algorithms is the frequency at which the measurement data is sampled. Because of this difference, the aircraft engine is described in a different form for each algorithm. In this section, the description of the aircraft engine is given first. Then, the descriptions of on-line and off-line diagnostic algorithms are given.

\section{Aircraft Engine Description}

An aircraft engine under consideration for on-line diagnostics is described by nonlinear equations of the following form:

$$
\begin{aligned}
& \dot{x}=\bar{f}\left(x, h_{k}, u_{c m d}, e\right) \\
& y=\bar{g}\left(x, h_{k}, u_{c m d}, e\right)+v
\end{aligned}
$$

The vectors $x, u_{c m d}$, and $e$ contain state variables, control command inputs, and environmental parameters, respectively. Health degradation of the engine is represented by the vector $h$ which contains health parameters. Health parameters are efficiencies and flow capacities of the engine components such as compressors and turbines. As they deviate from the nominal (healthy) baseline, the performance delivered by each component degrades. Since health degradation progresses gradually over time, the health parameter vector is treated as a constant at the time scale where on-line diagnostics is performed. The subscript $k$ of the health parameter vector indicates the sample index at the time scale where off-line diagnostics is performed. For given inputs, the nonlinear functions $\bar{f}$ and $\bar{g}$ generate the state derivative vector $\dot{x}$ and the sensor output vector $y$, respectively. The sensor outputs are corrupted by the white noise vector $v$.

While the aircraft engine is described in the form of equation (1) for on-line diagnostics, it is described in the following form for off-line diagnostics:

$$
Y_{k}=\bar{g}_{S S}\left(h_{k}, U_{k}, E_{k}\right)+V_{k}
$$

The vectors $Y, U$, and $E$ contain steady-state values of sensor outputs, control command inputs, and environmental parameters, respectively. The subscript $k$ indicates the sample index. The nonlinear function $\bar{g}_{S S}$ is equivalent to $\bar{g}$ in equation (1) at steady state. The vector $V$ represents "steadystate" white noise, and its magnitude is much smaller than that of actual noise $v$ contained in the raw measurements. The steady-state noise represents small biases that exist at the time of data sampling.

In the off-line trend monitoring problem, the health parameter vector is treated as time variant; the health condition can change over the time interval between the sample points. Because of the gradual nature of health degradation, the time interval can be rather long. Depending on how the off-line trend monitoring is performed, the time interval can be a few flights or a few days.

\section{On-Line Algorithm: Hybrid Kalman Filter}

The objective of on-line fault detection is to detect faults as early as possible from the observed engine outputs. To achieve this objective, the sensor outputs in equation (1) are continuously processed in real time so that any shift induced by faults can be detected. The on-line diagnostic algorithm, which pursues the above objective, is based on the hybrid Kalman filter (HKF) technique (refs. 8 and 9). The HKF is a uniquely structured Kalman filter which utilizes a nonlinear on-board engine model (OBEM) of the following form: 


$$
\begin{aligned}
& \dot{x}_{\mathrm{OBEM}}=f\left(x_{\mathrm{OBEM}}, h_{\mathrm{OBEM}}, u_{c m d}, z\right) \\
& y_{\mathrm{OBEM}}=g\left(x_{\mathrm{OBEM}}, h_{\mathrm{OBEM}}, u_{c m d}, z\right)
\end{aligned}
$$

This form is similar to the assumed form of the aircraft engine in equation (1). The vector $x_{\mathrm{OBEM}}$ contains the state variables of the OBEM while the vector $z$ contains the measured parameters which define the flight condition. The vector $h_{\text {OBEM }}$ represents the health baseline of the OBEM. By utilizing the state and output vectors of the OBEM, the following HKF equation is obtained:

$$
\begin{aligned}
& \dot{\hat{x}}=A\left(\hat{x}-x_{\mathrm{OBEM}}\right)+K(y-\hat{y}) \\
& \hat{y}=C\left(\hat{x}-x_{\mathrm{OBEM}}\right)+y_{\mathrm{OBEM}}
\end{aligned}
$$

The vectors $\hat{x}$ and $\hat{y}$ represent the estimate of $x$ and $y$ of the plant in equation (1), respectively. The state-space matrices $A$ and $C$ are derived through the linearization of the nonlinear plant model (in the present case, OBEM). The matrix $K$ represents the Kalman gain. Similar to the general linear Kalman filter approach, the matrices $A, C$, and $K$ are derived at multiple operating conditions to cover a wide operating range of the aircraft engine. Once derived, these matrices are saved in table lookup form for real-time execution of equation (4).

The Kalman filter, in general, is able to accurately estimate the sensor outputs as long as the plant operates under the conditions expected by the Kalman filter. When the plant experiences unexpected events such as faults, the estimation performance of the Kalman filter becomes poor, causing an increase in the residuals, $(y-\hat{y})$. Therefore, fault detection can be achieved by detecting such an increase in the residuals. To detect fault-induced shifts in the residuals, weighted sum of squared residuals (WSSR) signals are constructed as follows:

$$
\begin{aligned}
\mathrm{WSSR}_{\mathrm{HKF}} & =(y-\hat{y})^{T} \Sigma^{-1}(y-\hat{y}) \\
\mathrm{WSSR}_{\mathrm{OBEM}} & =\left(y-y_{\mathrm{OBEM}}\right)^{T} \Sigma^{-1}\left(y-y_{\mathrm{OBEM}}\right)
\end{aligned}
$$

where

$$
\Sigma=\operatorname{diag}\left[\sigma^{2}\right]
$$

The vector $\sigma$ represents the standard deviation of the sensor measurements. The square matrix $\Sigma$ normalizes the residual vectors $(y-\hat{y})$ and $\left(y-y_{\text {OBEM }}\right)$. The fault indicator signals, $\mathrm{WSSR}_{\mathrm{HKF}}$ and $\mathrm{WSSR}_{\mathrm{OBEM}}$, indicate the existence of faults; they will increase when the engine experiences faults. To detect faults, these signals are compared against preestablished thresholds. Fault detection is declared when at least one of the two fault indicator signals exceeds a threshold. As demonstrated in reference 9, the utilization of the two fault indicator signals improves the fault detection capability since these signals have different sensitivities to different types of faults.

The HKF designed at any particular health condition eventually loses its estimation accuracy as the engine degrades over its lifetime, and thus the fault indicator signals will increase. This is due to the fact that the discrepancy between the design health condition of the HKF and the actual health condition of the engine increases over time. In the HKF approach, the design health condition is defined by the vector $h_{\mathrm{OBEM}}$ at which the OBEM operates and also by the health condition at which the matrices $A, C$, and $K$ are derived.

In references 8 and 9, it is shown that the HKF is able to maintain its estimation performance as long as the health baseline of the OBEM remains in the vicinity of the engine's health condition. Thus, the HKF-based on-line fault detection algorithm is able to maintain its effectiveness by periodically updating the health baseline of the OBEM to a new condition as follows:

$$
h_{O B E M}=\hat{h}_{k}
$$

The vector $\hat{h}_{k}$ represents the estimate of the health parameter vector $h_{k}$ in equation (1). This estimate is provided by the offline trend monitoring algorithm, which will be discussed in the following section. The update process for the HKF is relatively simple; it is completed by feeding the estimated health degradation values into the OBEM. The matrices $A, C$, and $K$ do not need to be redesigned as the health baseline of the OBEM is updated. This relatively simple update process is a major benefit of the HKF approach.

\section{Off-Line Algorithm: Extended Kalman Filter}

The objective of off-line trend monitoring is to track the health condition of an engine over its lifetime. This objective is accomplished by accurately estimating the health parameter vector $h_{k}$ in equation (2) from the steady-state sensor outputs $Y_{k}$. The off-line diagnostic algorithm used in this study is based on a derivative of the extended Kalman filter (EKF) technique (ref. 10). The EKF is similar to the general linear Kalman filter except that a nonlinear plant model is successively re-linearized so that the validity of a linear plant representation is maintained as the plant moves from one operating condition to another. Therefore, a nonlinear plant model functions as part of the algorithm in the EKF approach. The nonlinear aircraft engine model used in the current study is given in the following form:

$$
\hat{Y}_{k}=g_{S S}\left(\hat{h}_{k}, U_{k}, Z_{k}\right)
$$

This form is similar to the assumed form of the aircraft engine in equation (2). The vector $U$ is the same vector that appears in 
equation (2). The vector $Z$ contains the steady-state values of measured parameters that indicate the flight condition. The subscript $k$ indicates the sample index. The vector $\hat{h}$ represents the estimate of the health parameter vector $h$, and this vector must be derived by the off-line trend monitoring algorithm.

The above nonlinear plant model can be presented in the following alternative form:

$$
\hat{Y}_{k}=G_{k \mid k-1}\left(\hat{h}_{k}-\hat{h}_{k-1}\right)+\hat{Y}_{k \mid k-1}
$$

where

$$
\begin{gathered}
\hat{Y}_{k \mid k-1}=g_{S S}\left(\hat{h}_{k-1}, U_{k}, Z_{k}\right) \\
G_{k \mid k-1}=\frac{\partial}{d \hat{h}} g_{S S}\left(\hat{h}_{k-1}, U_{k}, Z_{k}\right)
\end{gathered}
$$

The vector $\hat{h}_{k-1}$ represents the health parameter vector estimated at the previous sample point, $k-1$. The matrix $G_{k \mid k-1}$ represents the influence coefficient matrix derived from the nonlinear function, $g_{s s}\left(\hat{h}_{k-1}, U_{k}, Z_{k}\right)$. Given the vectors $\hat{h}_{k-1}, U_{k}, Z_{k}$, and $Y_{k}$, the health parameter vector at the sampling point $k$ is estimated as follows (ref. 6):

$$
\hat{h}_{k}=\hat{h}_{k-1}+L\left(Y_{k}-\hat{Y}_{k \mid k-1}\right)
$$

where

$$
L=P_{0} G_{k \mid k-1}^{T}\left(G_{k \mid k-1} P_{0} G_{k \mid k-1}^{T}+R\right)^{-1}
$$

The matrices $P_{0}$ and $R$ represent the error covariance and measurement covariance, respectively. In the general Kalman filter approach (both linear and extended), the error covariance matrix is updated as the new measurement data become available (ref. 10). This matrix, however, may diverge unless the number of available measurements is greater than or equal to the number of health parameters to be estimated. In general, the number of sensors installed on an aircraft engine is less than the number of health parameters. To avoid the divergence, the error covariance matrix is kept constant. Otherwise, the matrix update must be done with a special treatment, such as the soft-constraint approach demonstrated in reference 11 .

Equations (9) through (12) represent the EKF algorithm. The algorithm updates its estimate as new data $Y_{k}, U_{k}$, and $Z_{k}$ become available. To check the validity of the estimated health condition, the following weighted sum of squared residuals is computed:

$$
W_{S S R} E K F=\left(Y_{k}-\hat{Y}_{k}\right)^{T} \Sigma^{-1}\left(Y_{k}-\hat{Y}_{k}\right)
$$

This signal is compared against a pre-determined threshold. If the signal exceeds the threshold, it is considered that the estimated health condition is inaccurate, and thus further investigation is needed to determine a cause of inaccuracy.

After validation, the estimated health condition $\hat{h}_{k}$ is used to update the health baseline of the OBEM as described by equation (6). Through this update, the effectiveness of the online fault detection algorithm is maintained in the presence of health degradation. The estimated health condition also gives valuable information for engine health management. The snapshot estimation at a sample point can be used to consider whether a maintenance action is necessary or not. Thus, condition-based maintenance is possible instead of time-based maintenance. Engine health management can be further improved by interpreting the history of the estimated health condition. The estimated health condition from the past to the present reveals the degradation profile under which a specific engine operated. From this information, the health condition at a future point can be anticipated, and necessary actions may be taken to improve the safety or efficiency of the engine operation.

\section{Application of the Integrated Methodology to an Aircraft Engine Model}

The algorithms described in the previous sections require a nonlinear plant model. More specifically, the on-line algorithm requires a nonlinear model that can be executed in real time. In this section, a description of the aircraft engine model is given. For the results presented in this paper, the same model used by the diagnostic algorithms is also used to represent a real engine. The health degradation profile that the real engine may undergo is also discussed.

\section{Engine Model}

The engine model used in this paper is a nonlinear simulation of an advanced high-bypass turbofan engine, a typical power plant for a large commercial aircraft. This engine model has been constructed as a component level model (CLM), which consists of the major components of an aircraft engine. The CLM represents highly complex engine physics while being designed to run in real time. Engine performance deviations from the nominal health baseline are modeled by adjustments to efficiency and flow capacity scalars of the following five components: Fan (FAN), Booster (BST), High-Pressure Compressor (HPC), High-Pressure Turbine (HPT), and Low-Pressure Turbine (LPT). There are a total of 10 adjustments that are called health parameters. The engine state variables, health parameters, actuator variables, and environmental parameters are shown in Table 1. 
TABLE 1.-ENGINE MODEL VARIABLES

\begin{tabular}{|l|l|}
\hline State Variables & $\begin{array}{l}\text { XNL, XNH, TMHS23, TMHS3 } \\
\text { TMHSBL, TMHSBC, TMHS41 } \\
\text { TMHS42, TMHS5 }\end{array}$ \\
\hline Health Parameters & FAN efficiency, FAN flow capacity \\
& BST efficiency, BST flow capacity \\
& HPC efficiency, HPC flow capacity \\
& HPT efficiency, HPT flow capacity \\
& LPT efficiency, LPT flow capacity \\
\hline Actuators & WF36, VBV, VSV \\
\hline Environmental Parameters & Altitude, Mach Number \\
& Ambient Temperature \\
\hline
\end{tabular}

There are a total of 11 measured parameters $(y$ and $z$ ) that are available to the digital control unit of this engine. Table 2 shows seven sensors $(y)$ along with their standard deviations given in percent of steady-state values at the ground maximum power condition. The control actions and diagnostics are based on those sensed variables. Table 3 shows four additional measured parameters $(z)$ along with their standard deviations given in their actual engineering units. These four parameters indicate the ambient and engine inlet conditions. The measurements of the inlet condition, $\mathrm{T} 2$ and $\mathrm{P} 2$, are used for parameter corrections (ref. 12).

TABLE 2.-STANDARD DEVIATIONS OF CONTROLS AND DIAGNOSTICS SENSORS

( $\sigma$ in Percent of Steady-State Values at

Ground Maximum Power Condition)

\begin{tabular}{|c|c|}
\hline Sensors $(y)$ & $\sigma(\%)$ \\
\hline XN12 & 0.25 \\
\hline XN25 & 0.25 \\
\hline P25 & 0.50 \\
\hline T25 & 0.75 \\
\hline PS3 & 0.50 \\
\hline T3 & 0.75 \\
\hline T49 & 0.75 \\
\hline
\end{tabular}

TABLE 3.-STANDARD DEVIATIONS OF AMBIENT AND ENGINE INLET SENSORS ( $\sigma$ in Actual Units)

\begin{tabular}{|c|c|}
\hline Sensors $(z)$ & $\sigma$ \\
\hline $\mathrm{T}_{\mathrm{amb}}$ & $5.0^{\circ} \mathrm{F}$ \\
\hline $\mathrm{P}_{\mathrm{amb}}$ & $0.1 \mathrm{psi}$ \\
\hline $\mathrm{T} 2$ & $5.0^{\circ} \mathrm{F}$ \\
\hline $\mathrm{P} 2$ & $0.1 \mathrm{psi}$ \\
\hline
\end{tabular}

The nonlinear engine model is used in the subsequent sections to represent a real engine in equation (1) and the engine models in equations (3) and (7) for on-line and off-line diagnostics. The engine model representing a real engine operates at given health conditions, and its flight condition is specified by the three environmental parameters listed in Table 1. This engine model operates in closed loop with a control system described in reference 9. In the current control architecture, the power lever angle (PLA) is converted to desired corrected fan speed (an indicator of thrust). The control system adjusts three actuation variables to cause the corrected measured fan speed to match the desired value. The closed-loop system runs in a simulation environment at the frequency of $50 \mathrm{~Hz}$.

The two engine models used for on-line and off-line diagnostics are identical except that they operate at different time scales. These two engine models operate at estimated health conditions, and their flight condition is specified by three measured parameters: $\mathrm{T}_{\mathrm{amb}}, \mathrm{P}_{\mathrm{amb}}$, and $\mathrm{T} 2$. From these three measurements, the engine models calculate the altitude, Mach number, and the temperature deviation from the standard day condition. The two engine models receive the three control commands (Table 1) generated by the control system.

In the current study, the same engine model is used to represent a real engine and the engine model for diagnostics. This, however, does not represent a realistic application environment; there will typically be a mismatch between the real engine and the engine model due to un-modeled and incorrectly modeled physical phenomena. To represent such a mismatch, a turbine clearance model (TCM) is added only to the engine model representing a real engine. The TCM captures the turbine clearance behavior with high fidelity, and its addition results in output mismatch between the real engine and the engine model at steady-state conditions and during transients.

\section{Health Degradation Profile}

Each aircraft engine degrades differently depending on the environmental conditions the engine is exposed to. For instance, a high concentration of sand or salt can accelerate fan or compressor degradation while tropical heat can accelerate turbine degradation. Thus, there is no such thing as a typical degradation profile that engines will undergo (refs. 13 and 14). To capture this randomness, health degradation profiles considered in this paper are generated as follows:

$$
\begin{array}{ll}
h_{k}^{i}=h_{k-1}^{i}+\left(\frac{\eta^{i}}{q}\right) \varepsilon_{k}^{i}, & \text { if } k>0 \\
h_{k}^{i}=\delta_{k}^{i}, & \text { if } k=0
\end{array}
$$

where

$$
\begin{aligned}
& k=0,1, \cdots, q \\
& i=1,2, \cdots, p
\end{aligned}
$$

The integers $q$ and $p$ indicate the number of sample points and the number of health parameters, respectively. Equation (14) gives the value of the $i^{\text {th }}$ health parameter at the $k^{\text {th }}$ sample point. The scalar $\eta^{i}$ specifies the maximum amount that the $i^{\text {th }}$ health parameter can deviate over $q$ sample points. The random number $\varepsilon$ is uniformly distributed over the range between 0 and 1 . At the initial point $k=0$, each health parameter is specified by $\delta$, a random number uniformly distributed over the range of $\pm 0.5 \%$. The initial health condition represents engine-to-engine variations due to manufacturing tolerance. 
With the above equation, each health parameter undergoes a unique degradation profile. The degradation profile depends on the scalar $\eta$ specified for each health parameter and the random number $\varepsilon$.

\section{Performance Evaluation}

In this section, the performance of the off-line trend monitoring algorithm is investigated first, using a specific degradation profile. The off-line algorithm estimates the engine health condition at each sample point. The estimated health condition is then used to update the on-line fault detection algorithm. After the health baseline update, the on-line algorithm's capability to detect sensor faults is evaluated. The engine to be diagnosed by both algorithms contains the TCM in order to represent model-plant mismatch that exists in the real environment.

\section{Off-Line Trend Monitoring}

The off-line trend monitoring algorithm in equations (9) through (12) receives the steady-state vectors $Y_{k}, U_{k}$, and $Z_{k}$ and estimates the engine health condition at each sample point. The time interval between the sample points is rather long as discussed earlier. The steady-state data used in this section are generated from the engine model in equation (1) through the following steps. First, a degradation profile that the engine model will undergo over its lifetime ( $q$ sample points) is generated using equation (14). The degradation profile specifies a unique health condition at each sample point. Then, at each sample point, the engine model is run at a steady-state cruise condition. The operating condition of the engine is specified by the health condition, PLA, and environmental parameters in Table 1. From the steady-state simulation run, one-second time histories of $y$, $u_{c m d}$, and $z$ are collected. Then, the noise-corrupted time histories are averaged to obtain the steady-state vectors $Y_{k}, U_{k}$, and $Z_{k}$.

In the real environment, the steady-state flight condition of the engine can vary from flight to flight even at cruise. To capture this variation, PLA, altitude, Mach number, and ambient temperature are randomly varied from sample point to sample point. The PLA is varied over the range between $62^{\circ}$ and $66^{\circ}$ (intermediate power at cruise). Altitude is varied over the range between 33,000 and 37,000 ft. Mach number is varied over the range between Mach 0.83 and 0.85 . The ambient temperature is varied within $\pm 30^{\circ} \mathrm{F}$ from the standard day condition.

During a preliminary evaluation study, it was found that the off-line trend monitoring algorithm had difficulty in estimating FAN flow and LPT flow. When the actual FAN flow and LPT flow deviated toward a certain direction from their initial condition values, the estimated FAN flow and LPT flow did not follow the actual values. Instead, these estimated values deviated toward the direction opposite of the actual FAN flow and LPT flow. In the current estimation problem where the number of unknown parameters (health parameters) is greater than the number of known parameters (sensor outputs), a unique solution does not exist. The trend monitoring algorithm estimates the health parameters in such a way that the difference between the engine and model outputs is minimized in a least squares sense, while simultaneously minimizing the difference in the estimated health conditions at the current and previous sample points. ${ }^{1}$ This approach may produce health parameter estimates that are inaccurate. To work around this problem, the following constraint is imposed: the estimated health parameters are constrained to change in the specific direction expected from the heuristic knowledge regarding health degradation. All estimated health parameters are not allowed to increase from the estimation values at the previous sample point, except for HPT flow and LPT flow which are not allowed to decrease. If an estimated health parameter changes in the direction opposite of that expected, then the estimation value at the previous sample point is used as the current estimation value.

Figure 3 shows the actual and estimated health conditions over 300 sample points of engine life. The estimated health parameters were generated under the constraint previously discussed, except for the first five sample points. During the
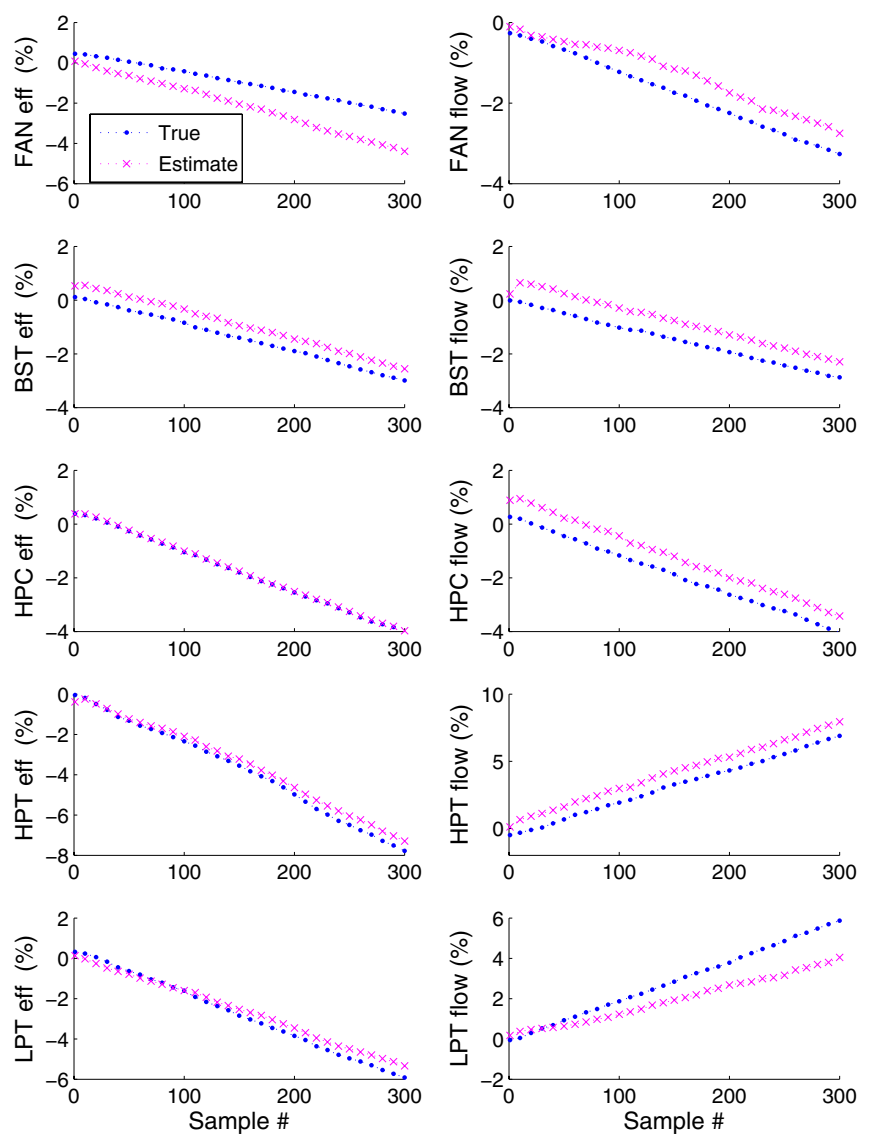

Figure 3.-Actual and estimated health degradation over the engine's lifetime.

${ }^{1}$ The algorithm given by equations (11) and (12) is equivalent to the maximum a posteriori estimator (refs. 15 and 16) and the minimum variance estimator (refs. 15 and 17). 
first five sample points, the health condition of the engine is maintained at the initial health condition representing engineto-engine variation due to manufacturing tolerance. The estimated health parameters which are initialized at the nominal health condition are allowed to change in any direction; constraints are not imposed on the estimated values during this period. The first five samples are simply used to let the estimated health parameters settle to any values in the presence of initial model-plant mismatch, which not only includes health condition mismatch but also the mismatch due to the TCM.

As can be seen in figure 3, the algorithm is able to follow the degradation profile quite well for three components: BST, HPC, and HPT. There are estimation errors, but the errors remain almost constant across the sample points. Thus, the deviation from the initial condition can be accurately tracked for these three components. The algorithm displays some difficulty in estimating the health parameters of FAN and LPT components; the estimation errors increase with time. The cause of this divergence is not clear. It may be due to the underdetermined nature of the current problem, or the location of the sensors may not be suited for estimating these health parameters. When this study was repeated using different patterns of health degradation profile, a similar tendency was observed. A total of five patterns of degradation profile, generated from equation (14), was investigated.

\section{Health Baseline Update of On-Line Fault Detection Algorithm}

The on-line fault detection algorithm in equations (3) and (4) receives the vectors $y, u_{c m d}$, and $z$ and generates the sensor output estimates and the on-board model outputs at each sample point with the time increment of $0.02 \mathrm{sec}(50 \mathrm{~Hz})$. Based on the residual vectors $(y-\hat{y})$ and $\left(y-y_{\text {OBEM }}\right)$, the two fault indicator signals in equation (5) are computed, and they are compared against pre-established thresholds. If at least one of the two fault indicator signals exceeds the threshold for 25 consecutive time steps, fault detection is declared as demonstrated in reference 9.

Before evaluating the fault detection capability of the online algorithm, the benefit through the integration of the online and off-line algorithms is investigated. As discussed earlier, the on-line fault detection algorithm will eventually lose its effectiveness as the engine degrades over time. This happens because the fault indicator signal values increase with the increase in discrepancy between the engine and the OBEM. To maintain diagnostic effectiveness, the health baseline of the OBEM must be updated periodically. This update is completed by feeding the estimated health condition values from the off-line trend monitoring algorithm to the OBEM. The importance of this health baseline update is illustrated in figure 4 where, over its lifetime of 300 sample points, the aircraft engine is subject to the specific health degradation profile shown in figure 3 . At each sample point,
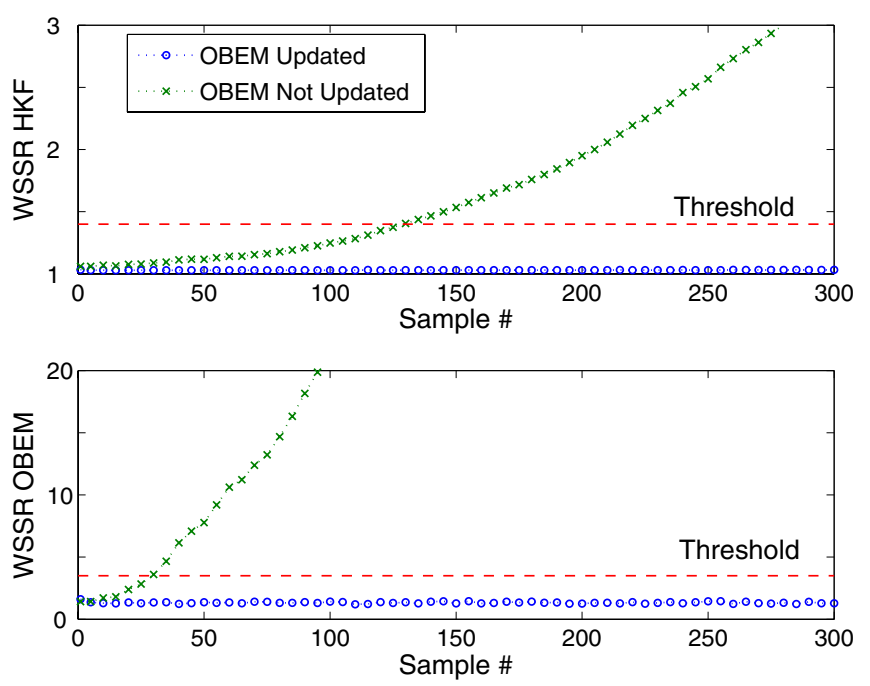

Figure 4.- Influence of engine health degradation on steadystate values of WSSR HKF $_{\text {and WSSR }}$ WBEM.

the engine and the on-line diagnostic algorithm are run at a specific cruise condition $\left(35,000 \mathrm{ft}\right.$ altitude, Mach $0.84,65^{\circ}$ PLA). Figure 4 shows the steady-state values of the fault indicator signals for the following two cases: 1) the health baseline of the OBEM maintained at the nominal condition and 2) the health baseline of the OBEM updated to the estimated health parameters shown in figure 3 . The dashed lines indicate fault detection thresholds. The threshold values were determined using health condition mismatches between the engine and the OBEM as done in references 8 and 9.

As can be seen in the figure, if the health baseline of the OBEM is not updated from the nominal condition, $\mathrm{WSSR}_{\mathrm{HKF}}$ exceeds the threshold around the $130^{\text {th }}$ sample point while WSSR $_{\text {OBEM }}$ exceeds the threshold around the $30^{\text {th }}$ sample point. This means that the fault detection algorithm will start misdiagnosing health degradation as a fault around the $30^{\text {th }}$ sample point. To avoid generating false alarms, the thresholds must be set at much higher values. However, doing so will compromise the fault detection capability and will increase the missed detection rate when the engine is at or near the nominal health condition.

When the health baseline of the OBEM is updated periodically, the fault indicator signals remain fairly constant over the lifetime of the degrading engine. In figure 4, the OBEM is subject to the estimated health condition shown in figure 3 , therefore, the estimation error in some of the health parameters increases over time. This increase in the estimation error seems to have a very minor influence on the fault indicator signals. The reason for this may be attributed to the nature of the off-line trend monitoring algorithm. The off-line trend monitoring algorithm estimates the health parameters in such a way that the difference between the engine and model outputs is minimized in a least squares sense (refs. 15 to 17). Thus, the estimated health parameters are not necessarily accurate, but they are ones that minimize the difference 
between the engine and model outputs. When these estimated health parameters are fed into the OBEM, the outputs of the OBEM match well with the engine outputs. Consequently, the fault indicator signals remain small.

Updating the health baseline of the OBEM has the effect of shifting the engine output reference to a new value. As illustrated in figure 1, the original reference at which the algorithm is designed becomes obsolete as the engine continues to degrade. By shifting the reference to a new value, such as point "a" in the figure, the on-line algorithm can detect the fault-induced shift, $\delta \Delta$, more reliably.

\section{On-Line Fault Detection: Sensor Bias Case}

The on-line algorithm's capability to detect faults is evaluated in this section using sensor biases. For this evaluation, the closed-loop engine is trimmed at a specific cruise condition $\left(35,000 \mathrm{ft}\right.$ altitude, Mach $\left.0.84,65^{\circ} \mathrm{PLA}\right)$ in the presence of health degradation and also a bias in a single sensor. Then, the engine and the on-line algorithm are run for $100 \mathrm{sec}$ at steady state. The smallest magnitude bias that is detected for each sensor is shown in Table 4. In this study, the aircraft engine and the OBEM are subject to, respectively, the actual and estimated health conditions in figure 3 at three sample points: $k=100,200$, and 300 .

From Table 4, it can be observed that the on-line algorithm performs consistently in the presence of health degradation; the detected bias magnitudes are almost the same at three health conditions, except for slight variations in the XN12 and XN25 sensors. For some of the sensors, detected bias magnitudes are not symmetric between the positive and negative directions. As discussed in reference 8 , health condition mismatch between the engine and the OBEM has an effect of counteracting a sensor bias to some extent. As a result, depending on the bias direction, it takes smaller or larger magnitude for the fault indicator signals to exceed the fault detection thresholds. This lack of symmetry, however, is not as prominent as the result in reference 8 .

TABLE 4.-MINIMUM SENSOR BIAS

DETECTED AT CRUISE WITH $65^{\circ}$ PLA

\begin{tabular}{|c|c|c|c|}
\hline & $\begin{array}{c}k=100 \\
(\sigma)\end{array}$ & $\begin{array}{c}k=200 \\
(\sigma)\end{array}$ & $\begin{array}{c}k=300 \\
(\sigma)\end{array}$ \\
\hline $\mathrm{XN12}$ & $2.6 /-4.5$ & $2.9 /-4.5$ & $2.9 /-4.4$ \\
\hline $\mathrm{XN25}$ & $3.2 /-3.8$ & $3.4 /-3.7$ & $3.3 /-3.6$ \\
\hline $\mathrm{P} 25$ & $1.3 /-1.3$ & $1.3 /-1.3$ & $1.3 /-1.3$ \\
\hline $\mathrm{T} 25$ & $2.1 /-2.2$ & $2.0 /-2.1$ & $2.0 /-2.1$ \\
\hline $\mathrm{PS} 3$ & $1.7 /-1.6$ & $1.7 /-1.7$ & $1.7 /-1.7$ \\
\hline $\mathrm{T} 3$ & $2.6 /-2.6$ & $2.6 /-2.6$ & $2.6 /-2.6$ \\
\hline $\mathrm{T} 49$ & $2.9 /-3.5$ & $2.9 /-3.5$ & $2.9 /-3.5$ \\
\hline & & & \\
\hline $\mathrm{T}_{\mathrm{amb}}$ & $0.3 /-0.3$ & $0.3 /-0.3$ & $0.3 /-0.3$ \\
\hline $\mathrm{P}_{\mathrm{amb}}$ & $0.5 /-0.5$ & $0.5 /-0.5$ & $0.5 /-0.5$ \\
\hline $\mathrm{T} 2$ & $0.4 /-0.4$ & $0.4 /-0.4$ & $0.4 /-0.4$ \\
\hline $\mathrm{P} 2$ & $-/-$ & $-/-$ & $-/-$ \\
\hline
\end{tabular}

As mentioned earlier, three sensor measurements, $\mathrm{T}_{\mathrm{amb}}$, $\mathrm{P}_{\mathrm{amb}}$, and $\mathrm{T} 2$ are used to define the flight condition for the OBEM. A bias in these sensors, therefore, causes the OBEM to operate at a flight condition different from the true condition. The table shows that biases of small magnitude are detected for these three sensors. The on-line algorithm is not able to detect a bias in the P2 sensor. This sensor is currently used for the correction of pressure measurements. Since both measured and estimated pressure values are corrected by the P2 value, a bias in this sensor does not increase the residuals. The reader should be reminded that the fault detection algorithm will not identify the biased sensor; it only indicates that a fault exists. After the detection of a fault, the identity or severity of the detected fault must be classified through the fault isolation process (ref. 18).

\section{Discussion}

The study in this paper reveals the benefit of integrating the on-line and off-line diagnostic algorithms. Through this integration, the on-line fault detection algorithm is able to maintain its diagnostic effectiveness as the aircraft engine degrades over its lifetime. The integration of the two algorithms, however, is not a trivial step. In this section, the practical aspects of the integrated approach are discussed.

One issue that influences the practicality of the integrated approach is the complexity involved in the update process of the on-line algorithm. If the update process involves a redesign of the entire on-line algorithm, such as the case for the piecewise linear Kalman filter approach (ref. 18), the redesign process may have to take place on a ground-based computer with human intervention. Furthermore, after the redesign process, the on-line algorithm must be uploaded to an on-board engine computer. Such complexity makes that approach impractical. It is desirable to keep the update process as simple as possible. In the case of the HKF, the algorithm is updated through a relatively simple process: by feeding the estimated health condition values to the OBEM. Thus, the HKF is well suited for the integrated approach.

Another issue that influences the practicality of the integrated approach is the location of the off-line trend monitoring algorithm. In general, a trend monitoring algorithm resides on a ground-based computer. In that case, the data for post-flight analysis and the off-line diagnostic results must be transmitted between the ground-based and on-board computers. There would be a number of communication and certification issues that would have to be addressed to achieve this integration.

The difficulties associated with off-board to on-board data transmission can be avoided if the off-line trend monitoring algorithm is capable of running on an on-board engine computer. Such a capability heavily depends on the off-line algorithm's robustness. As discussed earlier, trend monitoring is generally an underdetermined problem, and therefore an infinite number of solutions exist. Under this circumstance, 
the off-line algorithm must generate a solution (estimated health condition) "close enough" to the true solution; otherwise the algorithm may become unstable. In this paper, a simple constraint was imposed on the EKF: the estimated health parameters were constrained to change in the expected direction. The constraint was based on heuristic knowledge regarding health degradation, and it improved the stability of the EKF. Such an additional step is necessary for obtaining a reasonable solution in the underdetermined problem.

Another way of improving the stability of the EKF is to utilize steady-state measurement data obtained at multiple operating conditions. At distinctly different operating conditions, the same health condition can induce different signatures in the measured engine outputs. The utilization of multi-point data augments the number of known parameters (sensor outputs) in the problem, and therefore can improve the stability and also estimation accuracy (refs. 19 and 20). Through this extra step, the robustness of the off-line algorithm may be improved, making the algorithm capable of running on an on-board engine computer.

\section{Conclusion}

A challenge in developing an on-line fault detection algorithm is making it adaptive to engine health degradation. If the algorithm has no adaptation capability, it will eventually lose its diagnostic effectiveness. To address this problem, the integration of on-line and off-line diagnostic algorithms was investigated. The off-line trend monitoring algorithm periodically estimates engine health condition over the course of engine's life. Based on the estimated health condition, the on-line fault detection algorithm is updated. Through this integration, the on-line fault detection algorithm maintains its effectiveness while the engine continues to degrade over time.

The integrated approach was investigated in a simulation environment using a nonlinear engine model. The evaluation result showed that this integration is essential to maintain online fault detection capability in the presence of health degradation. Practical issues of the integrated approach were also discussed. The communication between the on-line and off-line algorithm can be made less complex if the off-line algorithm is operated on an on-board engine computer. To make this possible, further research is needed in the area of off-line trend monitoring.

\section{References}

1. Merrill, W.C., DeLaat, J.C., and Bruton, W.M., 1988, "Advanced Detection, Isolation, and Accommodation of Sensor Failures - Real-Time Evaluation," Journal of Guidance, Control, and Dynamics, 11, pp. 517-526.

2. Luppold, R.H., Roman, J.R., Gallops, G.W., and Kerr, L.J., 1989, "Estimating In-Flight Engine Performance Variations Using Kalman Filter Concepts,” AIAA Paper AIAA-89-2584.
3. Kerr, J.L., Nemec, T.S., and Gallops, G.W., 1992, "Real-Time Estimation of Gas Turbine Engine Damage Using a ControlBased Kalman Filter Algorithm," Journal of Engineering for Gas Turbines and Power, 114, pp. 187-195.

4. Brotherton, T., Volponi, A., Luppold, R., and Simon, D.L., 2003, "eSTORM: Enhanced Self Tuning On-board Real-time Engine Model," Proceedings of 2003 IEEE Aerospace Conference.

5. Doel, D.L., 1994, "TEMPER - A Gas Path Analysis Tool for Commercial Jet Engines," Journal of Engineering for Gas Turbines and Power, 116, pp. 82-89.

6. Volponi, A.J., 1994, "Sensor Error Compensation in Engine Performance Diagnostics," ASME Paper 94-GT-58.

7. Mathioudakis, K., Kamboukos, Ph., and Stamatis, A., 2002, "Turbofan Performance Deterioration Tracking Using NonLinear Models and Optimization Techniques," ASME Paper GT-2002-30026.

8. Kobayashi, T., and Simon, D.L., 2006, "Hybrid Kalman Filter Approach for Aircraft Engine In-Flight Diagnostics: Sensor Fault Detection Case," ASME Paper GT2006-90870.

9. Kobayashi, T., and Simon, D.L., 2006, "Hybrid Kalman Filter: A New Approach for Aircraft Engine In-Flight Diagnostics," NASA/TM-2006-214491.

10. Gelb, A., Kasper, J.F., Nash, R.A. Jr., Proce, C.F., and Sutherland, A.A. Jr., 1974, “Applied Optimal Estimation,” The MIT Press, Cambridge, Massachusetts.

11. Dewallef, P., Leonard, O., and Mathioudakis, K., 2004, "OnLine Aircraft Engine Diagnostics Using a Soft-Constrained Kalman Filter," ASME Paper GT2004-53539.

12. Volponi, A.J., 1999, "Gas Turbine Parameter Corrections," Journal of Engineering for Gas Turbines and Power, 121, pp. 613-621.

13. Wulf, R.H., 1979, "CF6 Jet Engine Performance Deterioration," AIAA Paper No. 79-1233.

14. Sasahara, O., 1985, "JT9D Engine/Module Performance Deterioration Results from Back to Back Testing," ISABE 857061.

15. Crassidis, J.L., and Junkins, J.L., 2004, "Optimal Estimation of Dynamic Systems," CRC Press, FL, pp. 63-96.

16. Volponi, A.J., 2003, "Foundation of Gas Path Analysis I," Von Kalman Institute Lecture Series: Gas Turbine Condition Monitoring and Fault Diagnosis.

17. Roth, B.A., Doel, D.L., and Cissell, J.J., 2005, "Probabilistic Matching of Turbofan Engine Performance Models to Test Data," ASME Paper GT2005-68201.

18. Kobayashi, T., and Simon, D.L., 2005, "Evaluation of an Enhanced Bank of Kalman Filters for In-Flight Aircraft Engine Sensor Fault Diagnostics," Journal of Engineering for Gas Turbines and Power, 127, pp. 497-504.

19. Stamatis, A., Mathioudakis, K., Berios, G., and Papailiou, K., 1991, "Jet Engine Fault Detection with Discrete Operating Points Gas Path Analysis," Journal of Propulsion and Power, 7, pp. 1043-1048.

20. Kobayashi, T., and Simon, D.L., 2005, "Hybrid Neural-Network Genetic-Algorithm Technique for Aircraft Engine Performance Diagnostics," Journal of Propulsion and Power, 21, pp. 751758. 


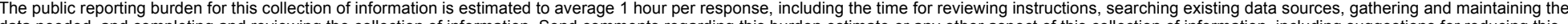

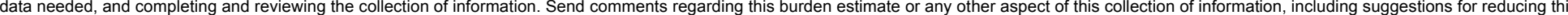

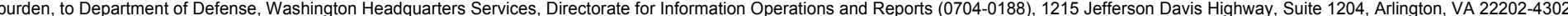

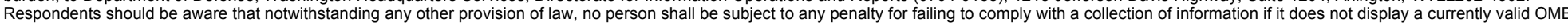
control number.

PLEASE DO NOT RETURN YOUR FORM TO THE ABOVE ADDRESS.

\section{REPORT DATE (DD-MM-YYYY) \\ 2. REPORT TYPE \\ 3. DATES COVERED (From - To)}

01-09-2007

Technical Memorandum

\section{TITLE AND SUBTITLE}

Integration of On-Line and Off-Line Diagnostic Algorithms for Aircraft Engine Health

Management

\section{5a. CONTRACT NUMBER}

5b. GRANT NUMBER

5c. PROGRAM ELEMENT NUMBER

6. AUTHOR(S)

Kobayashi, Takahisa; Simon, Donald, L.

\section{5d. PROJECT NUMBER}

5e. TASK NUMBER

5f. WORK UNIT NUMBER

WBS 122711.03.11.03.04.01

\section{PERFORMING ORGANIZATION} REPORT NUMBER

E-16132

National Aeronautics and Space Administration

John H. Glenn Research Center at Lewis Field

Cleveland, Ohio 44135-3191

\section{SPONSORING/MONITORING AGENCY NAME(S) AND ADDRESS(ES)}

National Aeronautics and Space Administration

Washington, DC 20546-0001

and

U.S. Army Research Laboratory

Adelphi, Maryland 20783-1145

\section{DISTRIBUTION/AVAILABILITY STATEMENT}

Unclassified-Unlimited

Subject Category: 07

Available electronically at http://gltrs.grc.nasa.gov

This publication is available from the NASA Center for AeroSpace Information, 301-621-0390

\section{SUPPLEMENTARY NOTES}

\section{ABSTRACT}

This paper investigates the integration of on-line and off-line diagnostic algorithms for aircraft gas turbine engines. The on-line diagnostic algorithm is designed for in-flight fault detection. It continuously monitors engine outputs for anomalous signatures induced by faults. The off-line diagnostic algorithm is designed to track engine health degradation over the lifetime of an engine. It estimates engine health degradation periodically over the course of the engine's life. The estimate generated by the off-line algorithm is used to "update" the on-line algorithm. Through this integration, the on-line algorithm becomes aware of engine health degradation, and its effectiveness to detect faults can be maintained while the engine continues to degrade. The benefit of this integration is investigated in a simulation environment using a nonlinear engine model.

\section{SUBJECT TERMS}

Aircraft engine health management; Fault detection; Kalman filter; On-board engine model

\begin{tabular}{|c|c|c|c|c|}
\hline \multicolumn{3}{|c|}{ 16. SECURITY CLASSIFICATION OF: } & \multirow{2}{*}{$\begin{array}{l}\text { 17. LIMITATION OF } \\
\text { ABSTRACT } \\
\text { UU }\end{array}$} & \multirow{2}{*}{$\begin{array}{l}\text { 18. NUMBER } \\
\text { OF } \\
\text { PAGES } \\
16\end{array}$} \\
\hline $\begin{array}{l}\text { a. REPORT } \\
\text { U }\end{array}$ & $\begin{array}{l}\text { b. ABSTRACT } \\
\text { U }\end{array}$ & $\begin{array}{l}\text { c. THIS } \\
\text { PAGE } \\
\text { U }\end{array}$ & & \\
\hline
\end{tabular}

SPONSORING/MONITORS ACRONYM(S)

NASA, ARL

11. SPONSORING/MONITORING REPORT NUMBER

NASA/TM-2007-214980; ARL-TR-4090 

